\title{
Google Earth Pro Verilerinden Oluşturulan Sayısal Yükseklik Modelleri ve Global Sayısal Yükseklik Modellerinin Doğruluk Değerlendirmesi
}

\author{
Adalet DERVişoĞLU ${ }^{1 *}$, Şaziye Özge ATiK², Ramazan Alper KUÇAK ${ }^{1}$, Mahmut Oğuz SELBESOĞLU ${ }^{1}$ \\ ${ }^{1}$ Istanbul Teknik Üniversitesi, Inşaat Fakültesi, Geomatik Mühendisliği Bölümü, 34469, Maslak, İstanbul. \\ ${ }^{2}$ Gebze Teknik Üniversitesi, Mühendislik Fakültesi, Harita Mühendisliği Bölümü, Kocaeli. \\ Sorumlu Yazar, e-posta: adervisoglu@itu.edu.tr \\ e-posta: soatik@gtu.edu.tr \\ e-posta: kucak15@itu.edu.tr \\ e-posta: selbesoglu@itu.edu.tr \\ ORCID ID: http://orcid.org/0000-0001-7455-4282 \\ ORCID ID: http://orcid.org/0000-0003-2876-040X \\ ORCID ID: http://orcid.org/0000-0002-1128-1552 \\ ORCID ID: http://orcid.org/0000-0002-1132-3978
}

Geliş Tarihi: 11.05.2021

Kabul Tarihi: 07.10.2021

Öz

Farklı ölçme ve uzaktan algılama teknikleri ile elde edilen verilerden üretilen Sayısal Yükseklik Modelleri (SYM) verileri yükseklik bilgisi gerektiren birçok uygulamada kullanılmaktadır. LIDAR (Light Detection and Ranging) teknolojisinin son dönemlerde gelişmesi ile araziye ait nokta bulutu verisi üretimi için havadan LIDAR tekniği, uygun arazi koşullarının sağlanması halinde cm doğruluğunda SYM'nin

Anahtar kelimeler

Google Earth Pro; SYM; SRTM; ASTER; Kriging üretilebileceği sistemler haline gelmiştir. Çalışmada, elipsoidal yükseklik verisine sahip havadan LIDAR yöntemiyle elde edilmiş nokta bulutu referans veri olarak kullanılarak beş farklı enterpolasyon yöntemi ile SYM'ler oluşturulmuş, Google Earth Pro(GEP)'dan iki farklı yoğunlukta elde edilmiş yükseklik verileri kullanılarak oluşturulan SYM'ler ile karşılaştııılmıştır. Yine LIDAR ile elde edilen SYM'leri, SRTM (Shuttle Radar Topography Mission) ve ASTER (Advanced Spaceborne Thermal Emission and Reflection Radiometer) global SYM'leri ile karşılaştırılmıştır. GEP'dan elde edilen SYM'lerinin diğer iki SYM'ine göre daha iyi sonuçlar verdiği görülmüştür. GEP ile üretilen SYM ile 3,44 m doğruluk elde ederken, SRTM ve ASTER GDEM verilerinin doğruluğu sırasıyla $4,05 \mathrm{~m}$ ve 5,88 m'dir.

\section{Accuracy Assessment of Global Digital Elevation Models and Generated Digital Elevation Models from Google Earth Pro Data}

\begin{abstract}
Digital Elevation Models (DEM) obtained by different sources are used in many applications that require height information. With the recent development of LIDAR (Light Detection and Ranging) technology, the aerial LIDAR technique is commonly used to collect point cloud data for producing DEM in $\mathrm{cm}$ accuracy. In the study, DEMs were created with five different interpolation methods using the point clouds. Firstly, DEM was produced with point groups of two different densities selected from Google Earth Pro. Point clouds obtained from airborne LIDAR were used as reference data. Thus, the effect of different point densities and interpolation methods on DEM production with Google Earth Pro was examined. Additionally, DEMs obtained with LIDAR were compared with SRTM (Shuttle Radar Topography Mission) and ASTER (Advanced Spaceborne Thermal Emission and Reflection Radiometer) DEMs. DEMs obtained from Google Earth PRO give better results than the other two DEMs. DEMs produced with GEP achieve an accuracy of $3.44 \mathrm{~m}$, while the accuracy of SRTM and ASTER GDEM data is $4.05 \mathrm{~m}$ and $5.88 \mathrm{~m}$, respectively.
\end{abstract}

Keywords

Google Earth Pro; DEM; SRTM; ASTER; Kriging 


\section{Giriş}

Sayısal Yükseklik Modeli (SYM); fiziksel yeryüzünün, konum ve tanımlı bir düşey datuma dayandırılmış yükseklik bilgilerini de içinde barındıran 3 boyutlu sayısal grafik gösterimidir. Sayısal Yükseklik Modeli; ABD Jeolojik Ölçmeler Dairesi (USGS) tarafından; "arazinin yükseklik bilgisinin, kullanılan ortak bir düşey datumda, $X$ ve $Y$ yönündeki düzenli aralıklarla sayısal gösterimi" olarak tanımlanmıştır.

SYM kullanılarak arazinin eğimi, eğim yönü, arazinin bakısı, drenaj ağları, havza sınırları, akış yolları ve görüş alanı içindeki noktaların belirlenmesi yapılabilir, stereo görüntü çiftleri üretilebilir SYM mühendislik, jeomorfoloji, hidroloji, peyzaj mimarisi ve arkeoloji dahil olmak üzere coğrafi bir temeli kullanan çok sayıda disiplin tarafından kullanılmaktadır. SYM üretimi için arazi yüzeyinde uygun biçimde dağılmış, konum $(X, Y)$ ve yüksekliği (H) bilinen noktalara intiyaç duyulmaktadır. Bu noktaların ve SYM'nin oluşturulmasında kullanım amacı ve beklenen mekansal doğruluğa bağlı olarak birçok yöntem ve teknoloji kullanılmaktır. SYM oluşturmak için toplanan verinin kalitesi uygulanan teknolojiye bağlı olup, veriler yersel ve uydulara dayalı ölçme teknikleri (total station, takeometre, GNSS, yersel lazer tarayıcılar vb.), hava fotogrametrisi, LIDAR, radar altimetresi ve interferometrik yapay açıklıklı radar (InSAR) ölçmeleri ile elde edilebilir.

Günümüzde sağladıkları yüksek doğruluk nedeniyle yerel ölçekli uygulamalarda sayısal fotogrametri ve LIDAR (Light Detection and Ranging) ile üretilen SYM'leri tercih edilmekte, Global ölçekli SYM üretiminde uydu bazlı stereo optik ya da radar görüntüleri veya SAR (sentetik açıklıklı radar) interferometri yöntemi tercih edilmektedir.

Yeryüzü kara parçalarının büyük bölümlerini kapsayan global sayısal yükseklik modelleri, uzaktan algılama yöntemleri ya da topografik haritaların sayısallaştırılması ile üretilmekte, ücretli ya da ücretsiz olarak sunulmaktadır. Bu modellerin yersel ve havadan ölçme yöntemleri ile elde edilen modellere tercih edilmelerinin başlıca nedenleri, son yıllarda anlamlı şekilde iyileşen veri doğrulukları, birçok çalışma için yeterli çözünürlükte ve geniş alanlarda geçerli olmaları ve kullanıcılara ücretsiz olarak servis edilmeleri gelmektedir. Erişimi zor bölgelere (çöller, kutup bölgeleri, sık ormanlık alanlar, geniş bataklık alanlar vb. gibi) ilişkin veri sağlamaları da tercih edilmelerinin önemli bir sebebidir (Erol vd.2020).

Ücretsiz olarak veri sağlayan global yükseklik modellerinden biri olan Shuttle Radar Topography Mission-Mekik Radar Topografya Misyonu (SRTM), NASA (National Aeronautics and Space Administration) tarafından gerçekleştirilen bir proje olup, hem C-bandı hem de X-bandı frekanslarında çalışan tek geçişli uzay kaynaklı interferometrik Sentetik Açıklıklı Radar (SAR) sistemi kullanarak 2000 yılında 11 gün sürede, Dünya yüzeyinin \% 80'ini temsil eden, $60^{\circ} \mathrm{K}$ ve $56^{\circ} \mathrm{G}$ arasındaki kara kütlelerinin yükseklik verilerini toplamıştır. İyileştirme çalışmalarından sonra SRTM SYM üç değişik versiyonda dağıtılmaktadır. Çözünürlüğü, 1", 3", 30"; veri türü RADAR; 2B Datumu WGS84; düsey datumu EGM96'dir (Int Kyn. 1)

ASTER (Advanced Spaceborne Thermal Emission and Reflection Radiometer-Gelişmiş Uzay Kaynaklı Termal Emisyon ve Yansıma Radyometresi), ilk versiyonu ile Haziran 2009'da veri sağlamaya başlamış olup, Terra üzerindeki ASTER ekipmanı tarafından toplanan stereo çift görüntüler kullanılarak oluşturulmuştur. $83^{\circ} \mathrm{K}$ enleminden $83^{\circ} \mathrm{G}$ enlemine kadar uzanır ve Dünya'nın kara kütlesinin yüzde 99'unu kapsar. ASTER GDEM(Global Digital Elevation Model), GeoTIFF formatında $1^{\circ} \times 1^{\circ}$ lik paftalar halinde $30 \mathrm{~m}$ grid aralıklı olarak kullanıcılara ücretsiz veri sağlamaktadır (Int Kyn. 2). ASTER GDEM'in çözünürlüğü $1^{\prime \prime}$ ve 3 ", veri türü Stereo görüntü; 2B Datumu WGS84; düşey datumu EGM96'dir.

Ücretsiz olması nedeniyle en çok tercih edilen SYM'leri olan SRTM ve ASTER GDEM'in yükseklik verisi doğruluklarının belirlenmesi amacıyla yapılmış çok sayıda çalışma bulunmakta olup, doğruluk analizinde farklı istatistiksel yaklaşımlar kullanılabilir. Çalışmalarda en çok kullanılan yöntem, modelden elde edilen yükseklik bilgisi verilerinin daha yüksek doğruluğa sahip yersel ve uydu bazlı 
konumlama tekniklerinden elde edilen yükseklikler ile verileri ile karşılaştırılması şeklindedir.

Global SYM'lerin Türkiye'yi kapsayan veri setleri üzerinde yapılan ilk çalışmalardan biri Bildirici vd. (2008) tarafından gerçekleştirilen projedir. O dönemde ücretsiz kullanım olanağı bulunan tek global SYM, SRTM olup, veri seti yerel yükseklikler ile karşılaştırılmış, $10 \mathrm{~m}$ civarında doğruluğa sahip olduğu bildirilmiştir.

Luana vd. (2015) Çin de yapmışoldukları çalışmada ASTER ve SRTM yükseklik modellerinin doğruluk analizlerini referans verisi olarak 1:50 000 ölçekli haritaların sayısallaştırılması sonucu elde edilen SYM kullanarak gerçekleştirmişlerdir. SRTM doğruluğu $\pm 13.74 \mathrm{~m}$, ASTER 1. Versiyon $\pm 42.11 \mathrm{~m}$, ASTER 2. Versiyon ise $\pm 12.12 \mathrm{~m}$ olarak bulunmuştur.

Varga ve Bašić (2015) Hırvatistan'da yaptıkları çalışmada farklı SYM'lerinin yükseklik verilerinin doğruluk analizlerini yapmışlardır. Karesel ortalama hatalar (KOH) SRTM30 +: 21,3 m, SRTM GDEM: 3,8 $\mathrm{m}$ ve ASTER GDEM: 7,1 m olarak bulunmuştur. En yüksek doğruluk, daha önce yayınlanan sürümlerden çok daha iyi olan SRTM GDEM sürüm 3 ile elde edilmiştir. Tüm modellerin engebeli ve ormanlık alanlarda daha kötü olduğu, düz ve çıplak arazilerde yeni nesil küresel DEM'ler SRTM GDEM ve ASTER GDEM'in son derece doğru sonuçlar verdiği görülmüştür.

Elkhrachy (2018) Suudi Arabistan Najran'da yaptığı çalışmada SRTM sürüm 3 ve ASTER sürüm 2 ile elde edilen SYM'lerinin doğruluğunu GPS ölçmeleri ve topografik haritadan elde edilen SYM ile karşılaştırmıştır. GPS referans verileri ile elde edilen doğruluk, SRTM ve ASTER DEM'leri için $\pm 6.87 \mathrm{~m}$ ve $\pm 7.97 \mathrm{~m}$ olarak bulunmuştur. Topografik haritadan yüksekliği referans olarak kullanarak elde edilen doğruluk ise, SRTM ve ASTER DEM'leri için $\pm 6.87 \mathrm{~m}$ ve $\pm 7.97 \mathrm{~m}^{\prime}$ dir.

Bildirici ve Abbak (2020), SRTM (1" çözünürlüklü) veri setini yerel SYM ve DGNSS izleri ile karşılaştırmışlardır. SRTM'in doğruluğu $\pm 7-9 \mathrm{~m}$ olarak bulunmuştur. Buna göre Türkiye ve yakın çevresinde SRTM doğruluğunun, global doğruluğuna göre daha iyi bir performansa sahip olduğunu bildirmişlerdir. Yaptıkları bir proje ile inceledikleri
ASTER GDEM verilerinin doğruluğunun ise $\pm 7-12 \mathrm{~m}$ arasında olduğunu bildirmişlerdir.

Erol vd. (2020) yaptıkları çalışmada ile, yüksek çözünürlüklü global SYM'ler olan ASTER GDEM, SRTM ile bölgesel Harita Genel Müdürlüğü DTED2 modellerinin doğruluklarını GNSS / nivelman verileri kullanılarak analiz etmişlerdir. Farklı topografik özellikteki alanları temsil eden üç ayrı GNSS/nivelman veri seti kullanılarak kontrol noktalarının dağılımının yanı sıra test alanı topografyasının SYM doğruluğuna etkisi incelenmiştir. Testler sonucu global SYM'lerinin doğruluğu $\sim 8.0 \mathrm{~m}$ iken bölgesel DTED2 SYM doğruluğu $\sim 6.0$ m olarak bulunmuştur.

Google Earth (GE), uydu fotoğraflarından ilk kez 2004 yılında oluşturulan ve sürekli güncellenen, coğrafi verilerin analizi için oluşturulmuş bir bilgisayar yazılımıdır. Temmuz 2005'te sadece Amerika Birleşik Devletleri'nin tamamına yakınının görece yüksek çözünürlükte uydu fotoğraflarının yer aldığı yazılımda, Haziran 2006'dan itibaren dünyadaki şehirlerin büyük bir bölümünün ayrıntılı uydu görüntüleri bulunmaktadır. Günümüzde neredeyse tüm dünyayı kapsayan yüksek çözünürlüklü görüntülere ulaşılabilmektedir.

Google Earth Pro (GEP), GE'nin güçlendirilmiş donanımlı hali olup 2015 te ücretsiz kullanıma açılmıştır. GEP, GE ile aynı görüntüleri kullanmakta ancak kullanıcılar için tasarlanmış ek araçlar sunmaktadır. GEP, aynı anda birden çok noktanın haritalanmasına ve demografik, grafik veri katmanlarına erişilmesine olanak tanır. Google Earth Pro ile görüntü üzerinde gelişmiş ölçümler yapılabilir, yüksek çözünürlükte çıktılar alınabilir, Etablolar, coğrafi bilgi sistemi dosyaları (ESRI shapefile (.shp) ve Maplnfo (.tab) ) formatlarıyla programa aktarılabilir, yüksek çözünürlükte sanal uçuş videoları oluşturulabilir.

GE ve GEP programları haritacılık, coğrafi bilgi sistemleri (CBS), çevre ve şehircilik, tapu kadastro, ulaştırma, ormancılık, tarım vb. birçok uygulama alanında etkin bir şekilde kullanılmaktadır. Uydu teknolojilerindeki ilerlemeye paralel olarak kullanılan yüksek çözünürlüklü görüntülerinde 
koordinat doğruluğu, ileri seviyelere ulaşmıştır. Özellikle 2008 yılından sonra GE/GEP programına yüklenen görüntülerin konumsal doğruluğunun yüksek olduğu bilinse de yüksek doğruluk gerektiren çalışmalarda çalışma yapılacak bölgede doğruluk analizinin yapılması birçok araştırmacı tarafından ifade edilmektedir.

GE/GEP programlarının ücretsiz olması ve erişim kolaylığı, akademik ve günlük amaçlara yönelik kullanımını artırmakta ve diğer Coğrafi Bilgi Sistemi yazılımları ile birlikte coğrafi bilginin erişilebilirliğine, otomasyonuna ve dijital olarak üretilmesine katkı sağlamaktadır(Atak, 2019).

Yine GE ve GEP da kullanılan Sayısal Yükseklik Modeli (SYM) ile ilgili ayrıntılı bilgiler güvenlik ve gizlilik politikaları nedeniyle yayınlanmadığından, birçok araştırmacı farklı uygulamalarda GE programı kullanımı nedeniyle oluşabilecek belirsizlikleri azaltmak ve bunları anlamak için doğruluk ve hassasiyet gerektiren çalışmalara yönelik kullanım öncesinde doğruluk analizinin yapılması gerektiğini ifade etmektedir (Potere, 2008) (Yu ve Gong, 2012).

Isioye ve Jobin (2012) yaptıkları çalışmada, üç farklı SYM'yi; SRTM 30, Sayısallaştırılmış Topografik harita ve GEP'i karşılaştırmışlardır. Sayısallaştırılmış topografik haritadan elde edilen SYM iyi bir sonuç verirken, GEP'in SRTM 30 verilerinden çok daha iyi performans gösterdiğini bildirmişlerdir.

El-Ashmawy (2016) Mısır da 3 farklı bölgede 200 er noktanın yüksekliklerini nivelman ile belirlemiş GE den elde ettiği yükseklikler ile karşılaştırmıştır. Yükseklik doğrulukları 3 bölge için, Maksimum Mutlak Hata (MAE) 3.72m, 6.39m, 8.78m; Ortalama Hata $(\mathrm{OH}) 0.51 \mathrm{~m}, 1.13 \mathrm{~m}, 1.52 \mathrm{~m}$; ve $\mathrm{KOH} 1.85 \mathrm{~m}$, $3.57 \mathrm{~m} 5.6 \mathrm{~m}$ olarak belirlenmiştir. $\mathrm{KOH}^{\prime}$ un düşük olduğu bölge yükseklik farkının az olduğu $(5 \mathrm{~m})$ bölge olup, $\mathrm{KOH}^{\prime}$ un en yüksek olduğu bölge yükseklik farkının çok olduğu $(25 \mathrm{~m})$ bölgedir. GE kullanıcılarının, kullanmadan önce yükseklik verilerinin doğruluğunu referans verilerle karşılaştırarak test etmeleri gerektiği sonucuna varmışlardır.

Wang vd. (2017) ABD de farklı 6 eyalet verileri ile yaptıkları çalışmada $G E$ yükseklik verilerini, $A B D$ Jeolojik Araştırma Ulusal Yükseklik Veri Kümesinden
(USGS NED) alınan yükseklik tarama verileriyle karşılaştırmışlardır. GE'den elde edilen yükseklik verilerinin doğruluğunun, ortalama mutlak hatanın (OMH)ME 1.32m Standart sapmasının $2.7 \mathrm{~m} \mathrm{KOH}$ 'un $2.27 \mathrm{~m}$ bulunduğu bildirilmiştir.

Atak (2019) GE görüntülerinin konumsal doğruluğunun, görüntülerin çözünürlüğüne ve çekim tarihine bağlı olarak değiştiğini, farklı bölgelerde / alanlarda değişken bir yapı sergilediği ancak rölatif olarak yüksek bir doğruluğa sahip olduğunu belirtmiştir.

Hu vd. (2020) yaptıkları çalışmada Poyang gölü bölgesinde GE ten elde ettikleri yükseklik verileri ile 1:10000 ölçekli topografik haritalardan üretilen yükseklik verilerini karşılaştırmışlardır. 15086 örnek grid noktası kullanmış, örnek noktalar rastgele üç gruba ayrılmış ve her örnek noktanın DEM yüksekliği ve GE yüksekliği mutlak hata değerleri hesaplanmıştır. Üç grupta DEM yüksekliği ile GE yüksekliği arasındaki ortalama mutlak hata sırasıyla $1.47 \mathrm{~m}, 1.48 \mathrm{~m}$ ve 1.46 olarak belirlenmiş ve üç grupta standart sapma 1.10-1.12 m arasında değişmiştir.

Bu çalışmada İzmir Bergama'da seçilen bir bölgede (Şekil 1), LIDAR yükseklik verileri kullanılarak beş farklı enterpolasyon yöntemi ile SYM'leri oluşturulmuş, bu SYM'leri referans veri olarak kullanılmış, GEP yükseklik verileri kullanılarak (beş farklı enterpolasyon yöntemi ve iki farklı yoğunlukta) oluşturulan SYM'leri ile karşılaştırılmış, doğruluk analizleri yapıImıştır. Yine LIDAR yükseklik verileri ile oluşturulan SYM'leri, SRTM (1" çözünürlüklü) ve ASTER SYM'leri ile karşılaştırılmışır. Çalışmanın akış diyagramı Şekil 2'de verilmiştir. 


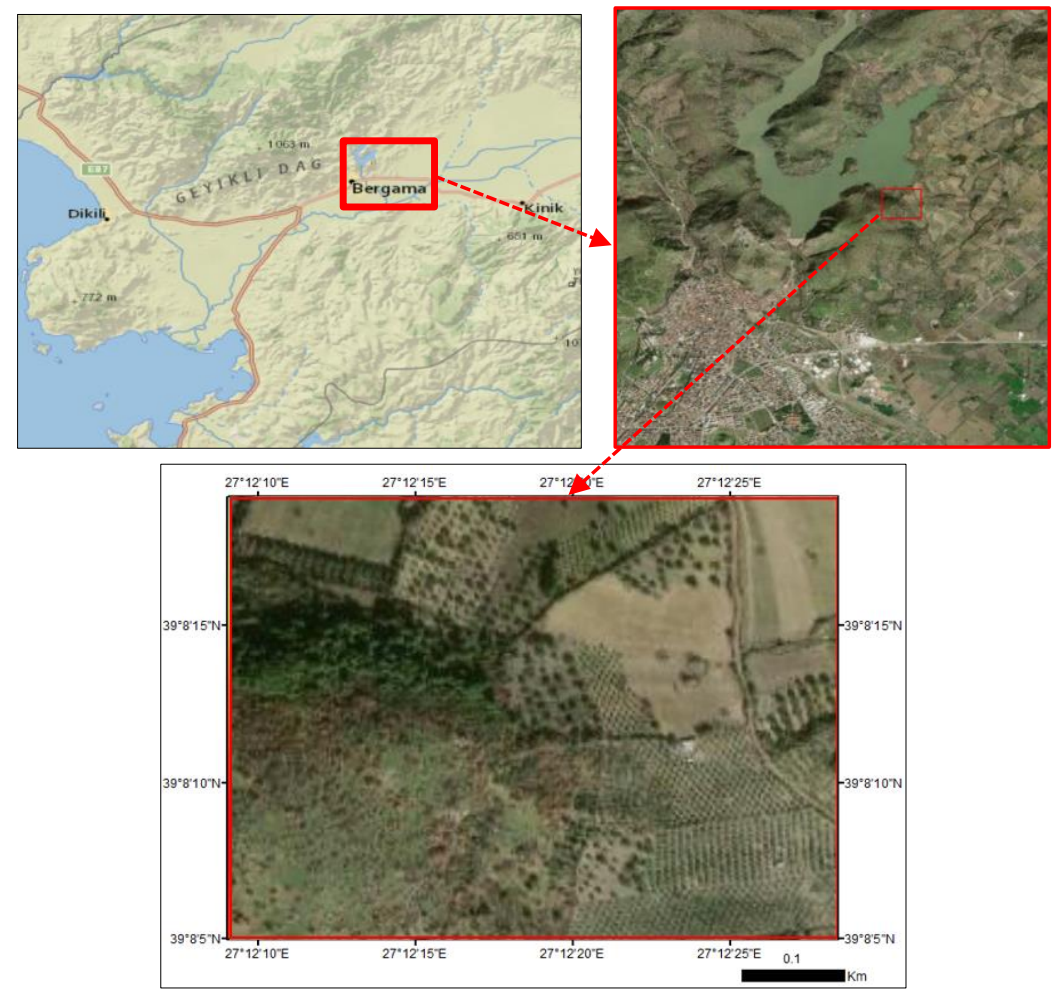

Şekil 1. Çalışma Bölgesi.

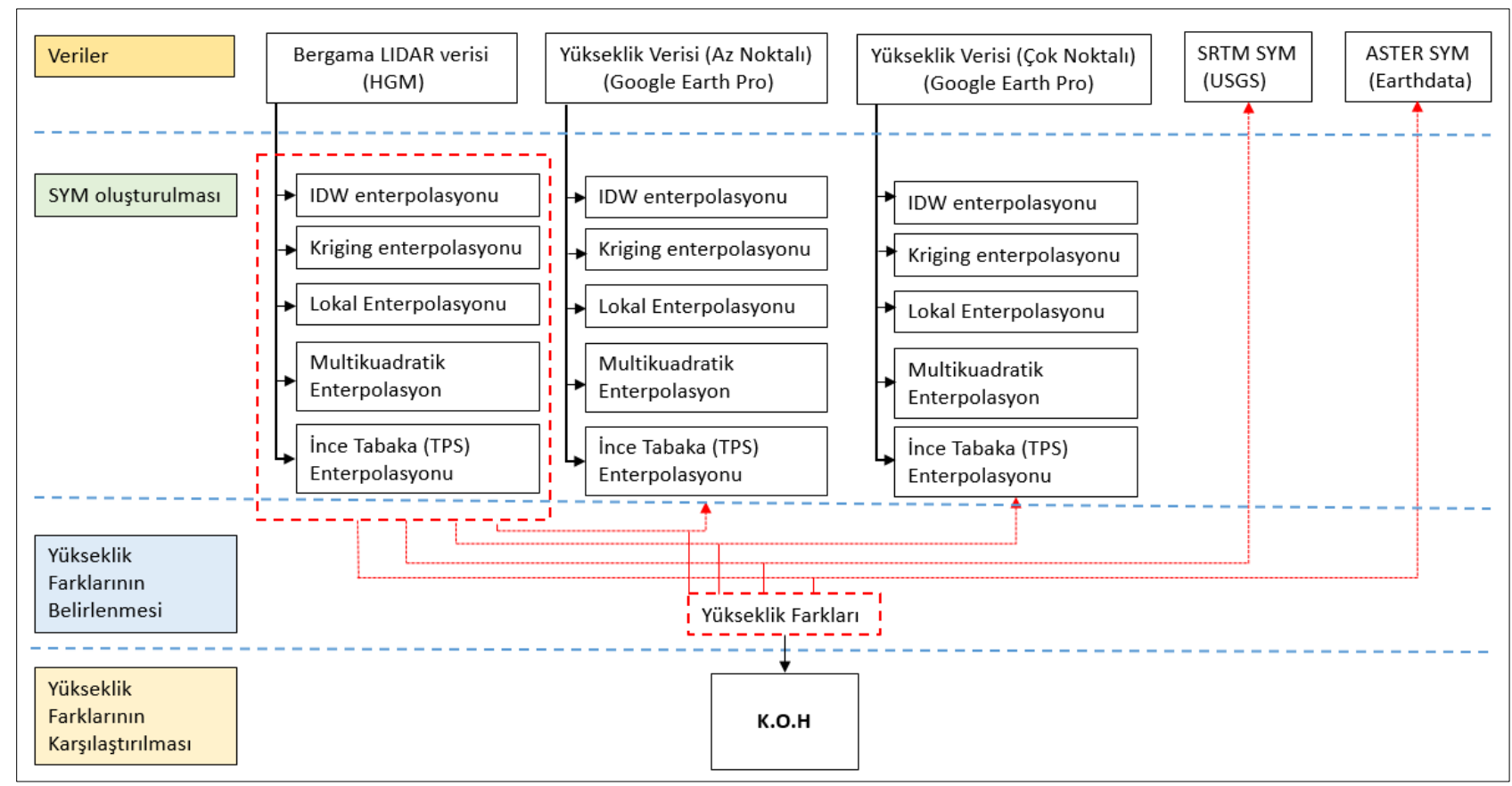

Şekil 2. Akış Diyagramı.

\section{Materyal ve Metot}

LIDAR (Light Detection and Ranging), havadan veya karadan sistemler ile kısa sürede büyük miktarlarda 3B verinin toplanmasını sağlayan bir ölçme tekniğidir. LIDAR sistemleri, 3B koordinat sisteminde yoğunluk değerleri (lazerin yüzeyden yansıma enerjisi = intensity) ve ayrıca genellikle sistemin dahili veya harici dijital kameraları tarafından sağlanan RGB değerleri ile 3B bir nokta bulutu oluşturur. (Kuçak vd.,2016 ; Kuçak vd., 2017, Kuçak vd., 2020).

Çalışmada kullanılan LIDAR verileri Harita Genel Müdürlüğü'nden temin edilen elipsoidal yükseklik 
verilerine sahip İzmir ili Bergama bölgesi hava LIDAR verileridir. 1200 m yükseklikten Optech Pegasus HA500 LIDAR sistemi ile $\mathrm{m}^{2}$ de yaklaşık 8 nokta ile taraması yapılmış Bergama bölgesinden seçilen $450 \times 430 m^{\prime}$ lik bir alanda noktasal verilerden beş farklı enterpolasyon yöntemi ile SYM'leri oluşturulmuştur. LIDAR verileri referans veri olarak kullanılacağından elipsoidal yükseklikten ortometrik yüksekliğe dönüşüm yapılmıştır. Yine GEP dan elde edilen ortometrik yükseklikler ve farklı enterpolasyon yöntemleri ile elde edilen SYM 'leri karşılaşıııılmıştır.

\subsection{LIDAR verileri ve Elipsoidal yükseklikten ortometrik yüksekliğe dönüşüm}

LIDAR elipsoidal yükseklik verilerini ortometrik yüksekliğe dönüştürmek için aynı bölgeye ait enlem ve boylam bilgisinden yararlanılarak ICGEM (International Centre for Global Earth Models) servislerinden (Int Kyn. 3), EGM 2008 (Pavlis 2012) geoit modellinden faydalanılarak, Bergama bölgesindeki enlem ve boylam bilgileri verilen bölge için geoid ondülasyonu (N) $38.79 \mathrm{~m}$ olarak hesaplanmıştır. Çalışma bölgesi küçük bir alanı kapsadığından hesaplanan geoid ondülasyonu (N) değeri, bütün bölge için kullanılmıştır.

\subsection{Enterpolasyon Yöntemleri}

\subsubsection{Lokal Polinom Enterpolasyonu}

Lokal Polinom Enterpolasyonu yöntemi ile arazi yüzeyi bir fonksiyon ile tanımlanabilmektedir (Yanalak 2002). Genel fonskiyon Eşitlik 1'deki gibi ifade edilebilir:

$$
z(x, y)=\sum_{k=0}^{n} \sum_{\substack{j=k-i \\ i=0}}^{k} a_{i j} x^{i} y^{j}
$$

$x, y$ noktanın düzlem koordinatlarını; $a_{i j}$ polinom katsayılarını; $n$ polinom derecesini göstermektedir. Eğer 2. Dereceden bir polinom kullanılırsa Eşitlik aşağıdaki gibi açılabilir:

$$
\begin{aligned}
& z(x, y)=a_{00}+a_{01} y+a_{10} x+a_{20} x^{2}+a_{11} x y+ \\
& a_{02} y^{2}
\end{aligned}
$$

Eşitlik 2'de $x$, y koordinatlar değerleri bilinen bir noktanın $z$ koordinatı hesaplanabilmektedir.
Koordinatları bilinen 6 nokta ile ikinci dereceden bir polinomun sabitleri tek anlamlı şekilde hesaplanabilir. Dayanak noktasının $6^{\prime}$ dan fazla olması durumunda dengeleme yapılabilmektedir.

\subsubsection{Multikuadratik Enterpolasyon}

Multikuadratik Enterpolasyon yönteminde arazi yüzeyi bütün dayanak noktaları kullanılarak ifade edilir. Harmonik seri veya trigonometrik fonksiyonlar yardımıyla dayanak noktalarından trend yüzeyi geçirilir. Bu yüzeyler iki yapraklı dairesel hiperboloid, dairesel paraboloid veya dairesel dik koni olabilir. Multikuadratik yüzey $\mathrm{m}$ sayıda aynı türden $Q$ yüzeyinin toplamında oluşur (Yanalak ve Baykal 2003). Eğer bu yüzeyler dik konilerden seçilirse multikuadratik yüzey:

$\sum_{j=1}^{m} C_{j}\left[\left(x_{j}-x\right)^{2}+\left(y_{j}-y\right)^{2}\right]^{1 / 2}=\Delta z$

olarak ifade edilir (Eşitlik 3). $C_{j}$ her bir $Q$ yüzeyinin işaretini ve yönünü belirleyen katsayılardır. $\Delta z$ ise artık yükseklik değeri olarak tanımlanır ve dayanak noktasındaki ölçülen yükseklik ile hesaplanan yükseklik arasındaki farktır. $C_{j}$ değerlerinin belirlenmesinde dayanak noktalarının bilinen $(x, y$, $\Delta z)$ koordinatlarından faydalanılır. Bir multikuadratik yüzey $C_{j}$ katsayılarının hesaplanması ile belirlenir. Buna göre $\left(\mathrm{x}_{0}, \mathrm{y}_{0}\right)$ noktasının yüksekliği $\left(z_{0}\right)$ Eşitlik 4 ile hesaplanır.

$z_{0}=z\left(x_{0}, y_{0}\right)+\sum_{j=1}^{m} C_{j}\left[\left(x_{j}-x\right)^{2}+\left(y_{j}-y\right)^{2}\right]^{1 / 2}$

\subsubsection{Ters Mesafe Ağırık Enterpolasyon Yöntemi}

$\mathrm{Bu}$ yöntem, enterpolasyon yapılacak noktadan uzaklaştıkça ağırlık kaybeden dayanak noktalarının ağırlıklı ortalamasına göre bir yüzey enterpolasyonu yapar. Standart IDW yönteminde bir P(i) noktasının enterpolasyon noktasının yüksekliği Eşitlik 5'teki gibi hesaplanabilir.

$z_{p}=\frac{\sum_{i=1}^{n} \frac{h_{i}}{d_{i}^{2}}}{\sum_{i=1}^{n}\left[\frac{1}{d_{i}^{2}}\right]}$

$\mathrm{z}_{\mathrm{p}}=\mathrm{P}$ noktasının hesaplanan yükseklik değeri

$\mathrm{h}_{\mathrm{i}}=$ dayanak noktasının yüksekliği

di = dayanak noktasının P noktasına uzaklığı 
$\mathrm{n}$ = dayanak noktası sayısı

Ters mesafe ağırlıklı enterpolasyon yöntemiyle, uzaktaki dayanak noktasının hesaplamaya olan etkisinin en aza indirilmesi amaçlanmaktadır. Standart yaklaşımda hesaba katılan dayanak noktası sayısında herhangi bir kısıtlama bulunmamaktadır. Bu durum hem hesap yükünü arttırmakta hem de enterpolasyon noktasının tahmin edilecek yükseklik değerine olumsuz yönde etki edebilmektedir. Uygulamada genellikle enterpolasyon noktasını merkeze alan daire veya dikdörtgen alanlar ile dayanak noktalarının sayısına sınırlama getirilmektedir (Yanalak 2002b).

\subsubsection{Kriging Enterpolasyonu}

Kriging enterpolasyonu, bilinen yakın noktaları kullanarak bilinmeyen noktalardaki değerleri kestiren mekânsal tahmin için jeoistatistiksel bir yöntemdir. Bu yöntem, matematiksel jeodezide yarıvariogram yapısal özellikleri kullanılarak doğrusal yansız tahmini optimal şekilde gerçekleştirebilir. Kriging yönteminde, tahmin edilen her bir nokta için varyans değeri hesaplanabilmektedir. Böylece tahmin edilen değerin bir güven ölçüsü ortaya konulmuş olur. Bu yaklaşım Kriging enterpolasyonunu diğer yöntemlerden ayıran en önemli özelliktir. Genel formül Eşitlik 6'da gösterilmiştir.

$N_{p}=\sum_{i=1}^{n} P_{i} N_{i}$

$\mathrm{N}_{\mathrm{p}}=\mathrm{P}$ noktasının hesaplanan yükseklik değeri

$\mathrm{P}_{\mathrm{i}}=$ her bir dayanak noktasının ağırlığı

$\mathrm{N}_{\mathrm{i}}$ = dayanak noktalarının geoit ondülasyon değeri

$\mathrm{n}=$ dayanak noktası sayısına karşılık gelmektedir.

Dayanak noktalarının geoit ondülasyon değerleri bilinmektedir. Ancak ağırık değerlerinin $\left(\mathrm{P}_{\mathrm{i}}\right)$ hesaplanması gerekmektedir. Kriging enterpolasyonunda bu ağırlık değerleri kestirim hata ortalaması sıfır ve varyansları minimum olacak şekilde hesaplanır (Yaprak ve Arslan 2008).

\subsection{5 ince Tabaka Eğrileri Enterpolasyonu}

Ince Tabaka Enterpolasyonu, kontrol noktaları arasında pürüzsüz bir enterpolasyon yüzeyi oluşturmayı amaçlamaktadır. Bu kapsamda dayanak noktaları kullanılarak enterpolasyon parametreleri hesaplanır. Yöntem matematiksel olarak aşağıdaki bağıntıyla ifade edilir (Eşitlik 7-9).

$F(u, v)=a_{0}+a_{1} u+a_{2} v+\sum_{i=1}^{N} f_{i} r_{i}^{2} \ln r_{i}^{2}$

$r_{i}^{2}=\left[r_{i}(u, v)^{2}\right]=\left(u-u_{i}\right)^{2}+\left(v-v_{i}\right)^{2}$

$\sum_{i=1}^{N} f_{i}=\sum_{i=1}^{N} f_{i} u_{i}=\sum_{i=1}^{N} f_{i} v_{i}=0$

Eşitlik 7, $a_{n}$ ve $f_{i}$ katsayıları çözümü için kullanılır. Bu eşitlikte, $u$ ve $v$ katsayıların çözüleceği nokta koordinatlarını ifade eder. $r$ ise parametrelerin çözüldüğü nokta ile diğer noktalar arasındaki Öklid mesafesidir. Hesaplanan katsayılardan $f_{i}$ ile ilgili toplamların sıfır olması gerekmektedir (Atik vd. 2020).

\subsection{Google Earth Pro üzerinden yükseklik verisi elde edilmesi}

Google Earth Pro üzerinden noktaların mümkün olduğunca homojen olarak dağılmasına dikkat edilerek $450 \times 430 \mathrm{~m}^{\prime}$ lik alan üzerinde rastgele az noktalı (2048 nokta/m² de yaklaşık 0.01 nokta) ve çok noktalı (8402 nokta/m² $\mathrm{m}^{2}$ de yaklaşık 0.04 nokta)

olmak üzere 2 farklı nokta kümesi oluşturulmuştur (Şekil 3a, Şekil 4a). GEP üzerinden seçilen noktalar GPX formatına çevrilmiş yükseklik verisine sahip bu noktalar ile (Şekil 3b, Şekil 4b) farklı enterpolasyon yöntemleri ile SYM leri elde edilmiştir. IDW enterpolasyon yöntemi ile elde edilen SYM'leri Şekil $3 c$ ve Şekil $4 c^{\prime}$ de verilmiştir. 


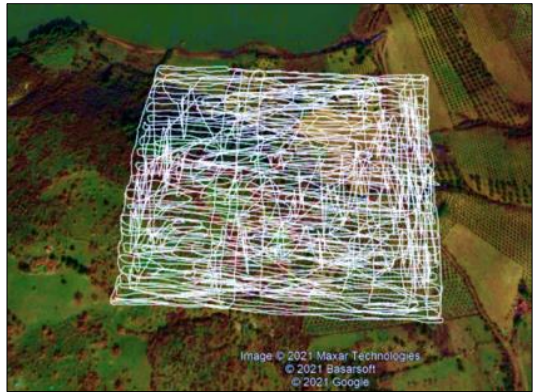

(a)

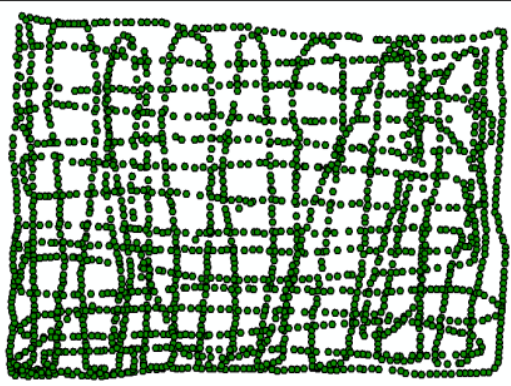

(b)

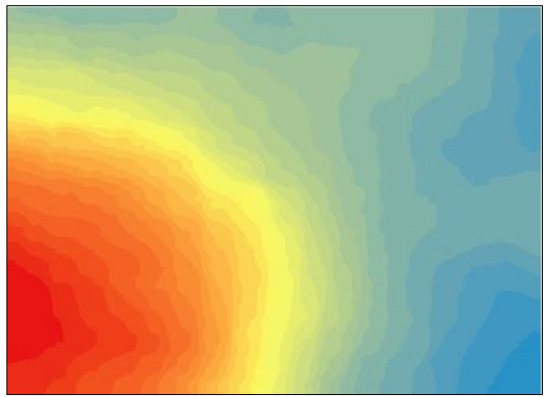

(c)

Şekil 3. (a) GEP üzerinde yapılan az noktalı rastgele tarama (b) elde edilen 2048 nokta (c) IDW ile oluşturulan SYM.

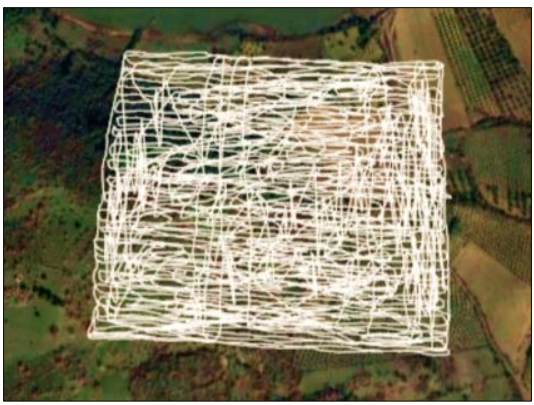

(a)

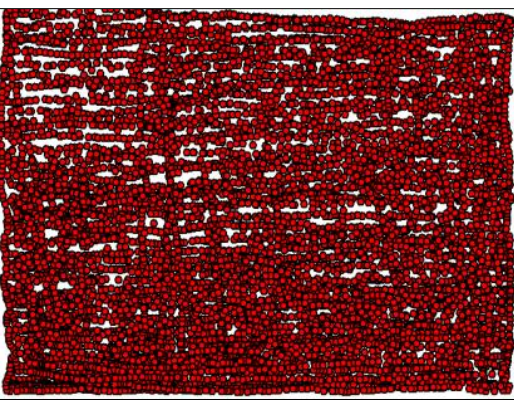

(b)

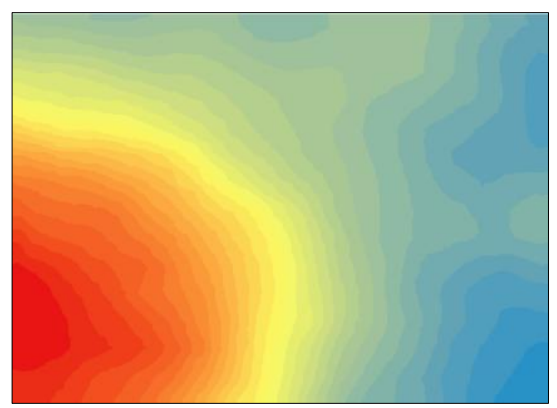

(c)

Şekil 4. (a) GEP üzerinde yapılan az noktalı rastgele tarama (b) elde edilen 8402 nokta (c) IDW ile oluşturulan SYM.

\subsection{SRTM ve ASTER GDEM SYM}

İndirilen SRTM (n39_e027_1arc_v3) ve ASTER (ASTGTMV003_N39E027_dem) SYM verilerinden

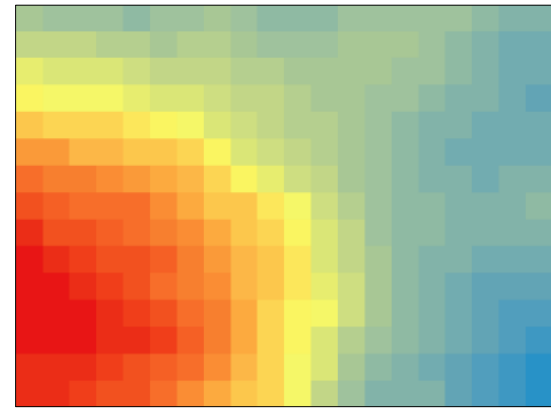

(a) çalışma bölgesi kesilmiş ve elde edilen SYM'leri Şekil 5 'te verilmiştir.

Şekil 5. (a) SRTM SYM (b) ASTER SYM.

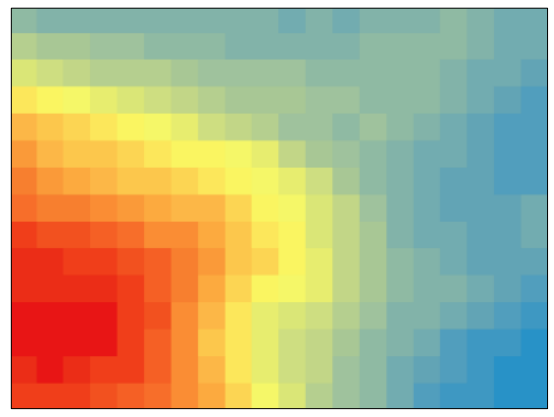

(b)

\section{5 Üç farklı yükseklik verisi ve beş farklı yöntem ile elde edilen SYM'leri}

LIDAR yükseklik verileri ile beş farklı enterpolasyon yöntemi kullanılarak oluşturulan SYM'leri ile GEP'den elde edilen yükseklik verileri ile yine beş enterpolasyon yöntemi kullanılarak oluşturulan SYM'leri Şekil 5'te verilmiştir.

\subsection{Doğruluk Analizleri}

Her bir yöntem referans veri ile karşılaştırılarak $\mathrm{KOH}$ hesapları yapılmıştır. Doğruluk analizi için arazi

üzerinde rastgele 90 test noktası seçilmiştir. Test noktalarının her bir modelde karşılık geldiği değerler belirlenerek LIDAR nokta bulutundan elde edilen model ile 5 farklı modelden elde edilen değerler arasındaki yükseklik farkları hesaplanmıştır. Bu farklar kullanılarak $\mathrm{KOH}$ hesaplanmıştır. $\mathrm{KOH}(\sigma)$ hesabı Eşitlik 10'da gösterilmiştir.

$\sigma=\sqrt{\frac{[v v]}{n-1}}$ 
$\checkmark$ referans SYM ile GEP' den elde edilen modelleri arasındaki farkı ifade eder. $\mathrm{n}$ değeri bilinen sayısını yani test noktalarının sayısını ifade eder.

LIDAR yükseklik verileri kullanılarak farklı enterpolasyon yöntemleri ile elde edilmiş SYM'leri ile GEP yükseklik verileri kullanılarak elde edilen SYM kullanılarak 90 rastgele noktada yapılan analizleri ile elde edilen $\mathrm{KOH}^{\prime}$ lar Çizelge $1^{\prime}$ de verilmiş̧ir. Yine LIDAR yükseklik verileri kullanılarak farklı enterpolasyon yöntemleri ile elde edilmiş SYM'leri ile SRTM ve ASTER SYM'leri 90 rastgele noktada karşılaştırılmış, elde edilen $\mathrm{KOH}^{\prime}$ lar Çizelge 1 'de verilmiştir.

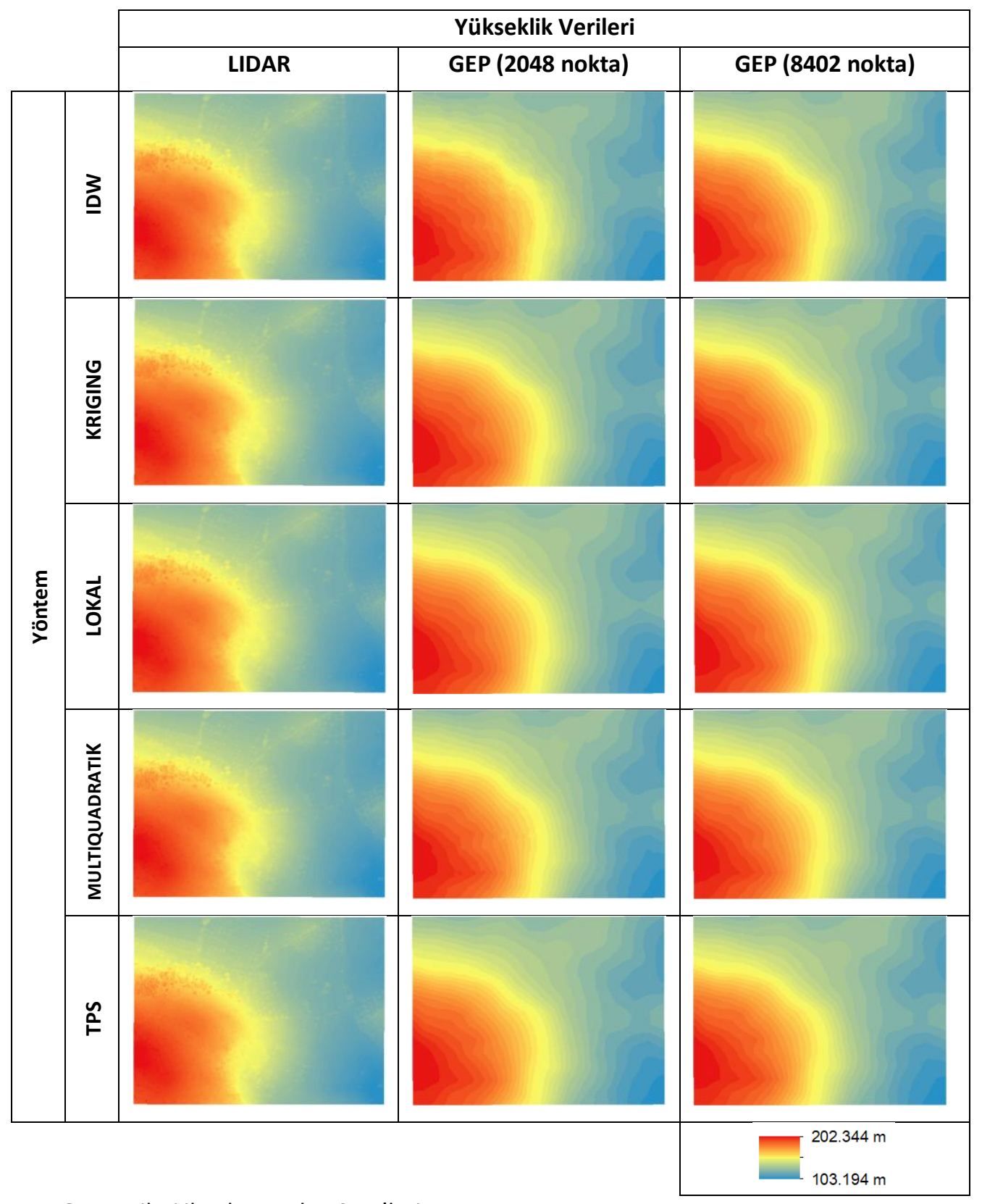

Şekil 6. LIDAR ve GEP verileri ile oluşturulan SYM'leri. 
Çizelge 1. K.O.H Hesapları ile Doğruluk Karşılaştırması.

\begin{tabular}{lcccc}
\hline & \multicolumn{5}{c}{ K.O.H (m) } \\
Referans SYM & $\begin{array}{c}\text { GEP SYM } \\
\text { (2048 nokta) }\end{array}$ & $\begin{array}{c}\text { GEP SYM } \\
\text { (8402 nokta) }\end{array}$ & $\begin{array}{c}\text { SRTM } \\
\text { SYM }\end{array}$ & $\begin{array}{c}\text { ASTER } \\
\text { SYM }\end{array}$ \\
\hline LIDAR SYM (Ters Mesafe Ağırlık/IDW) & 3.50 & 3.53 & 4.14 & 5.9 \\
LIDAR SYM (Kriging) & 3.44 & 3.45 & 4.05 & 5.88 \\
LIDAR SYM (Lokal Polinom) & 3.58 & 3.57 & 4.46 & 6.43 \\
LIDAR SYM (Multikuadratik) & 3.90 & 3.83 & 4.79 & 6.68 \\
LIDAR SYM (Ince Plaka Eğrileri/TPS) & 3.92 & 3.90 & 4.87 & 6.73 \\
\hline
\end{tabular}

\section{Sonuç}

LIDAR verileri ile oluşturulan beş farklı SYM referans veri olarak kullanılmış, GEP yükseklik verilerinden 2 farklı yoğunlukta veri ve beş farklı yöntemle oluşturulan SYM'leri ile karşılaştırılmıştır. Yine aynı referans veriler SRTM ve ASTER SYM'leri ile karşılaştırılmıştır. Oluşturulan GEP SYM'lerinin SRTM ve ASTER SYM'lerinden daha iyi sonuçlar verdiği görülmüştür.

GEP verileri ile elde edilen SYM ne rastgele seçilen 90 nokta ile yapılan doğruluk değerlendirmesinde K.O.H \pm 3.44 - 3.92m aralığında belirlenmiştir. Sonuçlara göre en iyi doğruluk az nokta ile Kriging enterpolasyon yöntemiyle $\pm 3.44 \mathrm{~m}$ olarak elde edilmiştir. En düşük doğruluk ise yine az nokta kullanılarak Multikuadratik enterpolasyon ile üretilen SYM'de $\pm 3.90 \mathrm{~m}$ olarak elde edilmiştir. Seçilen çalışma alanında en yüksek ve en düşük nokta yükseklikleri arasında yaklaşık 99.1 m'lik bir fark bulunmaktadır. Yükseklik farklarının çok olmadığı düz alanlarda GEP'den elde edilen nokta yükseklikleri ile LIDAR verilerinden elde edilen yükseklik verileri karşılaştırıldığında farkların $\mathrm{cm}$ mertebesinde olduğu gözlemlenmiştir. iki farklı nokta yoğunluğunda GEP yükseklik verileri kullanılarak yapılan enterpolasyonlar da kullanılan nokta sayısı değiştikçe, model doğruluğunda anlamlı değişim olmadığı görülmüştür. Seçilen alanın 450x430m'lik küçük bir alan olmasının bu sonuçta etkili olduğu söylenebilir. GEP yükseklik verilerinin doğruluk değerlendirmesinde, farklı referans verilerinin kullanıldığı çalışmalar mevcuttur. Çeşitli ölçeklerde topografik paftalardan üretilen SYM'leri, nivelman yöntemi ile üretilen çok sayıda nokta verisi, ulusal yükseklik ağı verileri bunlardan birkaçıdır. Bu çalışmanın literatüründe verilen, farklı referans verileri ile GEP, SRTM ve ASTER GDEM doğruluklarını araştıran çalışmalar ile bu çalışmanın sonuçları karşılaştırılmıştır (Çizelge 2). Doğruluk değerlerindeki farklılıkların referans verilere bağlı olduğu söylenebilir.

Bu çalışmada yüksek doğruluklu LIDAR verisi referans veri olarak kullanıldığı için güvenilir bir doğruluk analizi sunulmaktadır.

Çizelge 2. Çalışmanın diğer çalışmalar ile karşılaştırılması (K.O.H değerleri $\mathrm{m}$ cinsinden verilmiştir).

\begin{tabular}{lccc}
\multicolumn{1}{c}{ Çalışma } & GEP & SRTM & ASTER \\
\hline El-Ashmawy (2016) & 5.6 & - & - \\
Wang vd. (2017) & 2.27 & - & - \\
Hu vd. (2020) & 1.46 & - & - \\
Luana vd. (2015) & - & 13.74 & 12.12 \\
Varga ve Bašić (2015) & - & 21.3 & 7.1 \\
Elkhrachy (2018) & - & 6.87 & 7.97 \\
Bildirici ve Abbak & - & $7-9$ & 7.12 \\
(2020) & & & \\
Bu çalışma & 3.44 & 4.05 & 5.88 \\
& & &
\end{tabular}

SRTM SYM ile referans SYM'leri karşılaştırıldığında $\pm 4.05-4.87 \mathrm{~m}$ aralığında doğruluklar elde edilmiş, kriging yöntemiyle oluşturulan referans SYM diğer yöntemlere kıyasla daha iyi sonuç vermiştir.

LIDAR yükseklik verileri ile oluşturulan SYM'leri ile ASTER SYM'i karşılaştırıldığında $\pm 5.88-6.73 \mathrm{~m}$ doğruluklar elde edilmiş ve yine kriging enterpolasyon yöntemi en iyi sonucu vermiştir.

Literatürde yapılan çalışmalara benzer şekilde SRTM, ASTER GDEM'den daha iyi sonuçlar vermiş; GEP verileri ile oluşturulan SYM ise SRTM den daha da iyi sonuçlar vermiştir. GEP üzerinden alınacak yükseklik verileri kullanılarak kriging enterpolasyon yöntemi ile oluşturulacak SYM'lerinin, SRTM SYM'nin kullanılabildiği tüm mühendislik ve akademik çalışmalarda rahatıkla kullanılabileceği 
söylenebilir. Eğimin yüksek olmadığı düz arazilerde SYM doğruluğu artacaktır. Gelecek çalışmalarda, farklı eğime sahip çalışma alanları seçilerek, arazinin düz ya da eğimli olmasının oluşturulacak SYM'nin doğruluğuna etkisi araştırılabilir.

\section{Teşekkür}

LIDAR verileri için Harita Genel Müdürlüğü'ne teşekkür ederiz.

\section{Kaynaklar}

Atak, V. O., 2019. Google Earth Uydu Görüntülerinin Konumsal Doğruluğu. Harita Dergisi, 85(161), 11-25.

Atik, M. E., Ozturk, O., Duran, Z., and Seker, D. Z. 2020. An automatic image matching algorithm based on thin plate splines. Earth Science Informatics, 13, 869882.

Bildirici, I. O., Ustun, A., Ulugtekin, N., Selvi, H. Z., Abbak, R. A., Bugdayci, I., and Dogru, A. O., 2008. Comparison of SRTM and 25K topographic maps in Turkey. In The Second international conference on cartography and GIS. Proceedings 1, January 21-24,2008, Borovets, Bulgaria.

Bildirici, İ. Ö., ve Abbak, R.A., 2020. Türkiye ve Çevresinde SRTM Sayısal Yükseklik Modelinin Doğruluğu. Geomatik, 5(1), 1-9.

El-Ashmawy, K. L., 2016. Investigation of the accuracy of google earth elevation data. Artificial Satellites, 51(3), 89-97.

Elkhrachy, I., 2018. Vertical accuracy assessment for SRTM and ASTER Digital Elevation Models: A case study of Najran city, Saudi Arabia. Ain Shams Engineering Journal, 9(4), 1807-1817.

Erol, S., Özögel, E., Kuçak, R. A., Erol, B., 2020. Utilizing Airborne LIDAR and UAV Photogrammetry Techniques in Local Geoid Model Determination and Validation. ISPRS International Journal of GeoInformation, 9(9), 528.

Erol, B., Işık, M., Erol, S., 2020. Global ve Bölgesel (Yüksek Çözünürlüklü) Sayısal Yükseklik Modellerinin Doğruluk Analizi Üzerine Bir Inceleme. Afyon Kocatepe Üniversitesi Fen Ve Mühendislik Bilimleri Dergisi, 20(4), 598-612.

Hu, F., Ge, J., Lu, C., Li, Q., Lv, S., Li, Y., ... and Lin, D., 2020. Obtaining elevation of Oncomelania Hupensis habitat based on Google Earth and it's accuracy evaluation: an example from the Poyang lake region, China. Scientific Reports, 10(1), 1-9.
Isioye, A. O., and Jobin, P., 2012. An Assessment of Digital Elevation Models (DEMs) From Different Spatial Data Sources. Asian Journal of Engineering, Sciences \& Technology, 2(1).

Kuçak, R. A., Kılıç, F. and Kısa, A, 2016. Analysis of terrestrial laser scanning and photogrammetry data for documentation of historical artifacts. The International Archives of Photogrammetry, Remote Sensing and Spatial Information Sciences, 42, 155.

Kuçak, R. A., Özdemir, E. and Erol, S., 2017. The segmentation of point clouds with k-means and ANN(artifical neural network). The International Archives of Photogrammetry, Remote Sensing and Spatial Information Sciences, 42, 595.

Kuçak, R. A., Erol, S., and İşiler, M., 2020. Comparative Accuracy Analysis of LIDAR Systems. Türkiye LIDAR Dergisi, 2(2), 34-40.

Luana, S., Hou, X., and Wang, Y.,2015. Assessing the Accuracy of SRTM Dem and Aster Gdem Datasets for the Coastal Zone of Shandong Province, Eastern China. Polish Maritime Research, 22(s1), 15-20.

Pavlis, N. K., Holmes, S. A., Kenyon, S. C., and Factor, J. K., 2012. The development and evaluation of the Earth Gravitational Model 2008 (EGM2008). Journal of geophysical research: solid earth, 117(B4).

Varga, M., and Bašić, T., 2015. Accuracy validation and comparison of global digital elevation models over Croatia. International journal of remote sensing, 36(1), 170-189.

Wang, Y., Zou, Y., Henrickson, K., Wang, Y., Tang, J., \& Park, B. J. (2017). Google Earth elevation data extraction and accuracy assessment for transportation applications. PloS one, 12(4), e0175756.

Yanalak, M., 2002. Sayısal arazi modellerinde yükseklik enterpolasyonu. Harita Dergisi, 69(128), 44-58.

Yanalak, M., 2002b. Yön ve Ters Uzaklık Ağırlıklı Ortalama ile Enterpolasyon. Harita Dergisi, 127, 55.

Yanalak, M., and Baykal, O., 2003. Digital elevation model based volume calculations using topographical data. Journal of Surveying Engineering, 129(2), 56-64. 
Yaprak, S., ve Arslan, E., 2008. Kriging Yöntemi ve Geoit Yüksekliklerin Enterpolasyonu. Jeodezi ve Jeoinformasyon Dergisi, (98), 36-42.

Yu, L., and Gong, P., 2012. Google Earth as a virtual globe tool for Earth science applications at the global scale: progress and perspectives. International Journal of Remote Sensing, 33(12), 3966-3986.

\section{internet kaynakları}

1-https://www2.jpl.nasa.gov/srtm/, (20.03.2021)

2-https://asterweb.jpl.nasa.gov/gdem.asp (20.03.2021)

3- http://icgem.gfz-potsdam.de/calcgrid (15.03.2021) 